\title{
Research on the Transformation and Upgrading of Xinjiang Jujube Industry in the Context of "Silk Road Economic Belt"
}

\author{
Bai Xiao ${ }^{1, \mathrm{a}}$, Kong $\mathrm{Na}^{2, \mathrm{~b}}$, Zhang Rong ${ }^{3, \mathrm{c}}$ \\ ${ }^{1}$ Postdoctoral Innovation Practice Base, Xinjiang Vocational and Technical College of Communications, Urumqi, Xinjiang, China \\ ${ }^{2}$ Science and Technology Project Service Center, Xinjiang Uygur Autonomous Region, Urumqi, Xinjiang, China \\ ${ }^{3}$ Faculty of Transportation and Management, Xinjiang Vocational and Technical College of Communications, Urumqi, Xinjiang, China
}

\begin{abstract}
Jujube planting in Xinjiang, China began in 1985, and then entered the rapid development stage of planting. By 2012, Xinjiang became the main jujube producing area in China. Due to its geographical advantage, jujube in Xinjiang, China is of high quality and has become another agricultural product with Chinese Xinjiang characteristics. However, jujube production in China has declined since 2013. Although China's Xinjiang planting area is still expanding, the price of jujube has been affected by a significant decline, and has been maintained at a low level in recent years. Farmers' income has decreased, and the bottleneck of jujube industry development has become prominent. Therefore, industrial transformation and upgrading is imminent. This paper combines in-depth analysis of jujube related data from 2007 to 2016, finds out the existing problems, and proposes the path for the transformation and upgrading of the jujube industry in Xinjiang, China. It aims to break through the bottleneck of jujube industry development and promote the healthy development of the industry.
\end{abstract}

\section{Introduction}

The "Silk Road Economic Belt" strategy was proposed by President Xi Jinping during his visit to Kazakhstan in September 2013.With its unique geographical location, Xinjiang has a core position in the Silk Road Economic Belt. The Central European - Urumqi Assembly Center operates three Central European trains every day. The number of Central European trains starting from Xinjiang has reached 20, reaching 26 cities in 19 countries in Central Asia and Europe. In the whole year of 2018, a total of 1,000 China-Europe trains were launched. At present, the assembly center has cooperated with 82 import and export enterprises inside and outside Xinjiang to establish a cargo alliance. The supply of trains has spread to more than ten provinces and cities such as Guangzhou, Zhejiang, Sichuan, and Shandong. The convenience of transportation has undoubtedly brought great convenience to the transportation of various agricultural products in Xinjiang.

In recent years, Xinjiang has mainly formed jujube varieties such as Jun jujube, gray jujube, pear jujube, winter jujube, and other representative jujube varieties in various regions, including Hami jujube in Hami region, jujube in Hotan region, and Aksu region, grey jujube, winter dates, gray dates in Ruoqiang County, and gray jujube in Qiemo area. Hami and Aksu's jujube have been approved as GI products. In recent years, jujube prices have been sluggish, many areas have reduced planting area, and many farmers have reduced planting investment due to cost issues. The development of the jujube industry has encountered bottlenecks. The existing research on Jujube mainly focuses on: Jujube information system design [1], Jujube industry supply chain management [2].Innovation research on marketing channel model [3], development status and variety selection of jujube industry [4-5], quality and safety of red jujube [6], opportunities and challenges of Xinjiang red jujube in the context of the New Silk Road Economic Belt [7], Research on the transformation and upgrading of Xinjiang jujube industry [8].Most of the existing research is focused on the planting and sales of Jujube. There are few studies on the path of Xinjiang's Jujube' industrial transformation and upgrading from the perspective of the overall development of the industry. Therefore, combining the background of the Silk Road Economic Belt and the analysis of the current state of jujube industry development in Xinjiang, this paper proposes the path of Xinjiang jujube industry transformation and development from the perspective of overall industrial development.

\section{Current Development of The Jujube Industry in Xinjiang,China in The Context of Silk Road Economic Belt}

\subsection{Introduction to the Plantation of Jujubes in China}

\subsubsection{Changes of the Overall Output of Jujube in China}

a41468463@qq.com b359168074@qq.com c274074331@qq.com 
It can be seen from Figure 1 that the output of jujube in 1973 was 395,765 tons, and the output of jujube in 2016 was 8.24 million tons, which was 20.82 times that in 1973. The jujube output has developed rapidly after steady growth. From 1973 to 1993, the output of jujube developed steadily. In 1993, the output of jujube was 1.32 times that of 1973; from 1993 to 2013, the output of jujube increased rapidly. In 2013, output was 12 times that of 1993, and from 2016 to 20 times that of 1993.Judging from the output trend, it is a continuous rise, but it has begun to slow down in 2017.

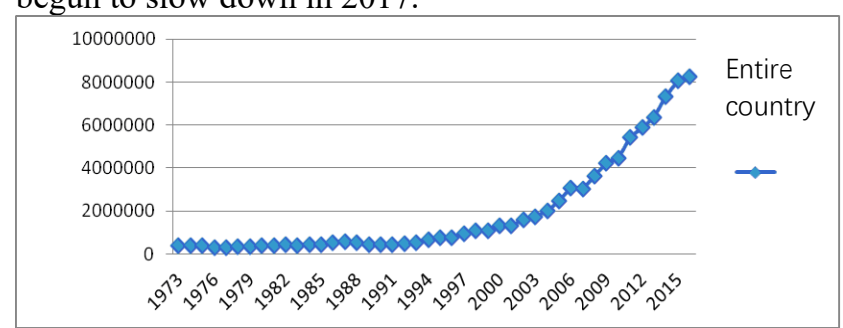

Fig1. Changes of Output of Jujubes in China

Data Sources: Department of Crop Management, Ministry of Agriculture

\subsubsection{Changes in the Output at Main Producing Areas in China}

Jujube related statistics began in 1973.Jujube's main producing areas are Hebei, Shandong, Henan, Shanxi, Shaanxi and other places. Jujube production accounts for more than $90 \%$ of China's total output (see Figure 2 for details).

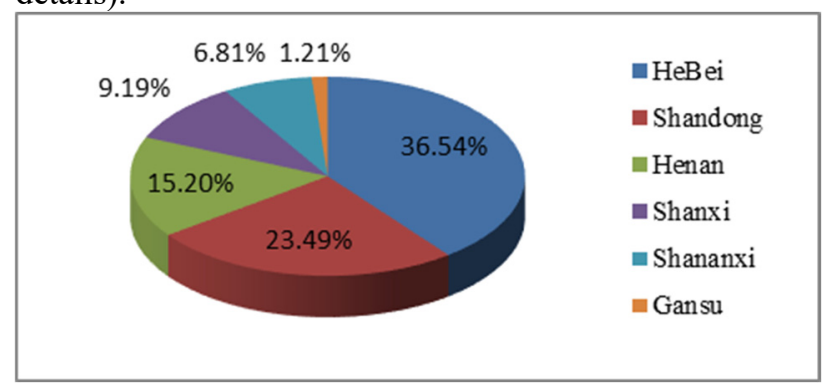

Fig2. Proportion of Jujube in China in 1973 (\%)

As of 2016, jujube is mainly produced in Xinjiang, Hebei, Shandong, Shaanxi, Shanxi, Henan and other places. Jujube output accounts for $95 \%$ of China's total jujube output (see Figure 3 for details).

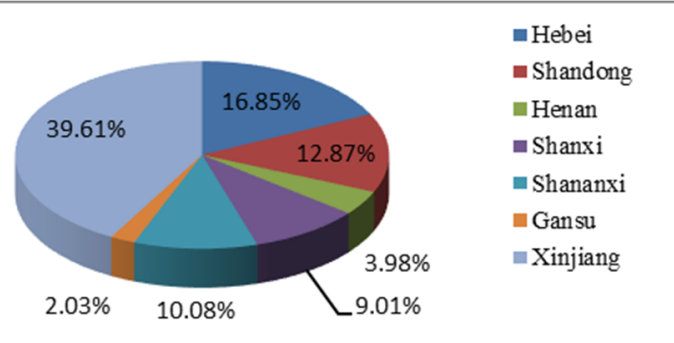

Fig3. Proportion of Jujube in China in 2016 (\%)

From the changes in Figure 2 to Figure 3, it can be seen that the jujube industry in Xinjiang has developed from scratch. In the end, Xinjiang has rapidly developed into a major jujube production area, accounting for $40 \%$ of China's total jujube output in 2016.Due to the huge increase in jujube output in Xinjiang, the proportion of other production areas in China's total output has decreased. The production area in Hebei decreased from $36.54 \%$ to $16.85 \%$, the production area in Shandong decreased from $23.49 \%$ to $12.87 \%$, the production area in Henan decreased from $15.20 \%$ to $3.98 \%$, and the production area in Shanxi basically maintained about $9 \%$. The area rose from $6.81 \%$ to $10.08 \%$, and the production area in Gansu rose from $1.21 \%$ to $2.03 \%$.

As can be seen from Figures 2 and 3, the main planting areas of jujube in China are concentrated in Xinjiang, Hebei, Shandong, Shaanxi, Shanxi, Henan and Gansu. From 1973 to 2016, the output of major jujube producing areas in China is shown in Table 1.It can be seen from Table 1 that Xinjiang started to introduce jujube planting in 1985, with a slow increase in the early stage, and entered a period of rapid development in 2005.In 2008, the production of jujube in Xinjiang began to increase exponentially. In 2012, Xinjiang surpassed the largest Jujube planting area in China-Hebei Producing Area in one fell swoop. As of 2016, Xinjiang produced 3.62 million tons of jujube, accounting for $40 \%$ of China's total jujube output. In other production areas, the contraction period began in 2009, and the output growth rate was small or basically maintained at the output level in 2009, and even the output of some provinces decreased.

\subsection{Current Development of the Jujube Industry in Xinjiang}

Xinjiang's main jujube producing area is located in the southern Xinjiang region south of the Tianshan Mountains. It has a continental climate, with long winters, severe cold, and short summers and hot summers. The climate is dry, with abundant light and heat, and sparse precipitation, because it is far from the ocean and surrounded by high mountains. With Tianshan as the boundary, the differences between the northern and southern Xinjiang are obvious. Northern Xinjiang has a temperate continental arid and semi-arid climate, and southern Xinjiang has a warm temperate continental arid climate. The average annual temperature in northern Xinjiang is -4 to $9{ }^{\circ} \mathrm{C}$, the annual precipitation is above 150 to $200 \mathrm{~mm}$, and the annual frostfree period is 140 to $185 \mathrm{~d}$; the annual average temperature in southern Xinjiang is $7 \sim 14{ }^{\circ} \mathrm{C}$, the annual precipitation is $25 \sim 100 \mathrm{~mm}$, and the annual frost-free period is $180 \sim$ $220 \mathrm{~d}$. The southern Xinjiang climate is suitable for jujube production, so the jujube industry in this area has developed rapidly.

\subsubsection{Jujube Plantation Area in Xinjiang}

Xinjiang's jujube has entered a period of rapid expansion since 2007.Xinjiang's main producing areas are concentrated in the Kashgar region, Aksu region, Bayinguoleng Mongolian Autonomous Prefecture region, Hotan region, and Turpan and Hami regions in northern Xinjiang. There are many varieties of jujube planted in Kashi region, and the area is relatively large. There is no specific jujube variety planted. The planting area has expanded rapidly from 22823 hectares in 2007 to 150555 hectares in 2016.The second is Aksu region. Jujube is 
mainly planted with gray jujube and jujube. It is mainly concentrated in Alar. The planting area expanded rapidly from 2007 to 2013, and a landslide occurred after 2013, reducing from 132,237 hectares to 2016.107,197 hectares, the planting area has been reduced, from the second largest planting area in Xinjiang to the third largest planting area; the Xinjiang Production Corps is distributed in various prefectures and prefectures in Xinjiang. The planting area statistics are the sum of the planting areas of the various divisions. For example, the Jujube production area of the 48th Regiment of the 3rd Division of the Xinjiang

Table1. Output of Jujube in China's Main Production Areas in 1973-2016 Unit: Ton

\begin{tabular}{|c|c|c|c|c|c|c|c|c|}
\hline Year & China & Xinjiang & Hebei & Shandong & Shaanxi & Shanxi & Henan & Gansu \\
\hline 1973 & 395765 & & 144600 & 92950 & 26940 & 36370 & 60140 & 4795 \\
\hline 1984 & 439150 & & 181500 & 101550 & 25050 & 41750 & 47300 & 4500 \\
\hline 1985 & 432037 & 972 & 132108 & 85675 & 24415 & 64864 & 78125 & 6626 \\
\hline 2002 & 1573698 & 12132 & 488031 & 403654 & 93491 & 138275 & 225017 & 60654 \\
\hline 2005 & 2488506 & 28620 & 807577 & 687372 & 188232 & 196858 & 268091 & 75450 \\
\hline 2007 & 3030623 & 87206 & 910315 & 927713 & 158738 & 192953 & 334740 & 111653 \\
\hline 2008 & 3634071 & 131413 & 929978 & 992862 & 514530 & 310405 & 366534 & 82771 \\
\hline 2009 & 4247773 & 289950 & 1077928 & 1077117 & 594350 & 395660 & 387830 & 94108 \\
\hline 2010 & 4468335 & 627319 & 1031025 & 994842 & 500320 & 421140 & 391864 & 117407 \\
\hline 2011 & 5426762 & 1057983 & 1253857 & 1016000 & 637270 & 577772 & 401262 & 119354 \\
\hline 2012 & 5887121 & 1453977 & 1258911 & 981121 & 678978 & 549325 & 405960 & 131114 \\
\hline 2013 & 6339973 & 1993660 & 1167677 & 910650 & 675998 & 551788 & 415495 & 147036 \\
\hline 2014 & 7345266 & 2574616 & 1312732 & 1189341 & 644592 & 614198 & 356367 & 144648 \\
\hline 2015 & 8075784 & 3054270 & 1385688 & 1072540 & 725849 & 815791 & 324165 & 168128 \\
\hline 2016 & 8240508 & 3264167 & 1388360 & 1060158 & 831005 & 742398 & 327563 & 167384 \\
\hline
\end{tabular}

By 2016, the planting area of Hotan jujube reached 59108 hectares, which is the fourth largest jujube planting area in Xinjiang; Bayinguoleng Mongolian Autonomous Prefecture jujube is mainly gray jujube, a small number of jujube, mainly planted in Ruoqiang area. Its planting area is similar to Hotan, showing a slow expansion trend, 4).
Production and Construction Corps is located in Bachu County of Kashgar. Its jujube varieties are the same as the jujube varieties in Kashgar. Its Xinjiang production corps jujube plantation expanded rapidly from 2007 to 2010, and from 2010.After a year of slow expansion, as of 2016, it still occupied the second largest planting area of Xinjiang Jujube with an area of 110,705 hectares; the jujube planted in Hotan area is relatively large, and the large ones can be comparable to the size of eggs. It is very famous, but the planting area has been expanding slowly.

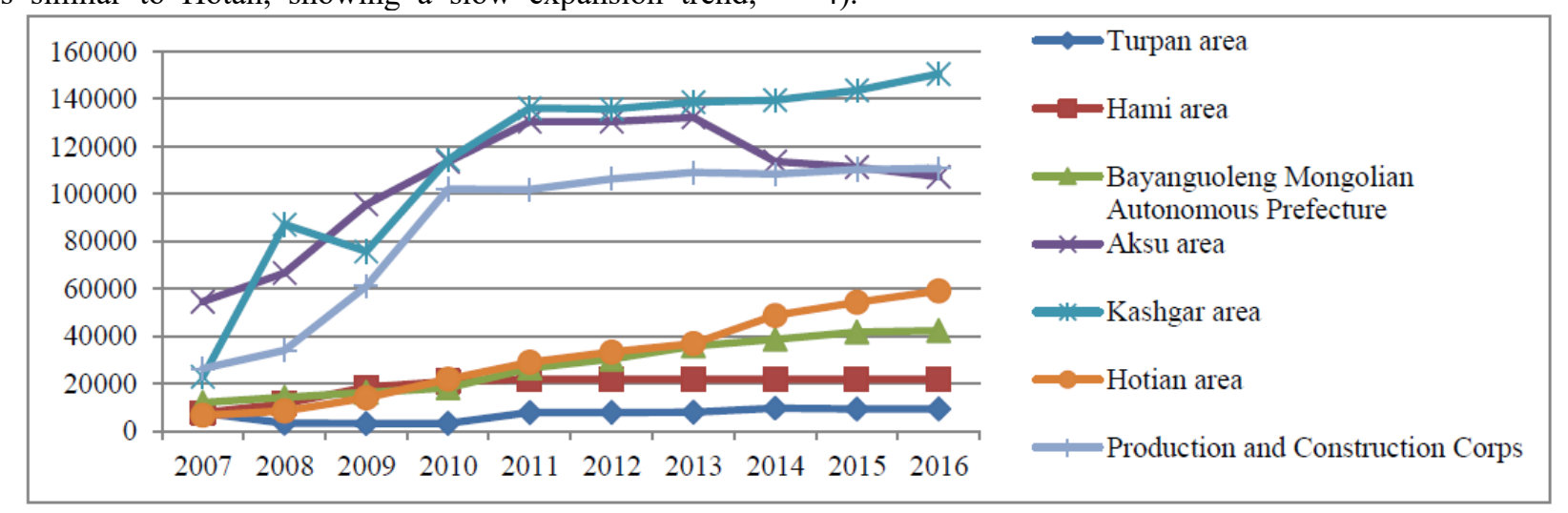

Fig4. Chart of Xinjiang Jujube Planting Area Unit: Hectare

Data Sources: Statistical Yearbooks of Xinjiang Prefectures

reaching 42305 hectares in 2016, which is the fifth largest jujube planting area in Xinjiang; the Hami area and Turpan area have not changed much, and basically maintained at a level. The Turpan area has basically been 21,906 hectares in recent years, and Hami is 9311 hectares(Figure

Aksu region maintained the second place in Xinjiang from

\subsubsection{Jujube Output of Various Plantation Regions in Xinjiang}

As can be seen from Figure 5, the output of Xinjiang Production and Construction Corps in Xinjiang's various production areas is the first in Xinjiang. From 2007 to 2016, its output has maintained the first momentum in Xinjiang, and its output increased in 2016.The output of
2007 to 2015, but declined in 2016, lower than the output of jujube in Kashgar region that year, ranking second; the output of jujube in Kashgar continued to rise steadily, from 10,190 tons in 2007 to 618,511 tons in 2016 , an increase of about 60 times; the Bazhou area, Hotan area, Hami area and Turpan area basically maintained a level, and there was no significant increase. It can be seen that Xinjiang Jujube's major production areas are Xinjiang Production 
and Construction Corps, Kashgar and Aksu.

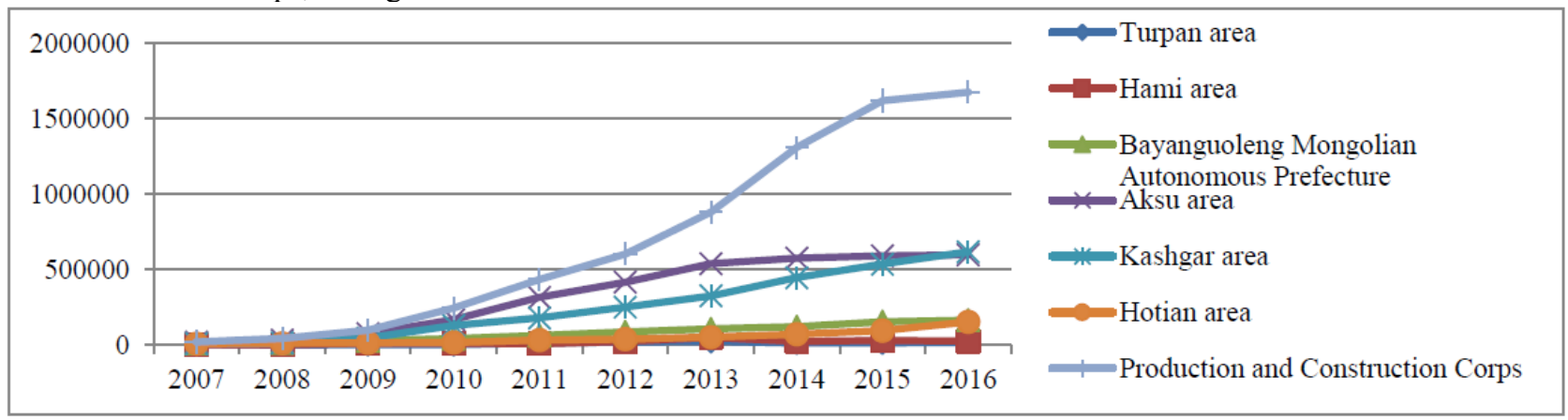

Fig5. Trend of the Jujube Output in Various Plantation Regions of Xinjiang Unit: Ton Data Sources: Statistical Yearbooks of Xinjiang Prefectures

\subsubsection{Production Efficiency of Each Jujube Plantation Area in Xinjiang}

Based on the above analysis, it can be seen that the area of Jujube in Xinjiang from large to small is: Kashgar, Aksu,
Xinjiang Production and Construction Corps, Hotan, Bazhou, and Hami. From the perspective of the output of each planting area, from high to low: Xinjiang Production and Construction Corps, Aksu, Kashi, Bazhou, Hotan, Hami and Turpan.

Table2. Production Efficiency of Each Jujube Plantation Area in Xinjiang Unit: ton/hectare

\begin{tabular}{|c|c|c|c|c|c|c|c|}
\hline $\begin{array}{c}\text { Unit } \\
\text { Production }\end{array}$ & $\begin{array}{c}\text { Turpan } \\
\text { area }\end{array}$ & $\begin{array}{c}\text { Hami } \\
\text { area }\end{array}$ & $\begin{array}{c}\text { Bayanguoleng Mongolian } \\
\text { Autonomous Prefecture }\end{array}$ & $\begin{array}{c}\text { Aksu } \\
\text { region }\end{array}$ & Kashgar & $\begin{array}{c}\text { Hotan } \\
\text { area }\end{array}$ & $\begin{array}{c}\text { Production and } \\
\text { Construction Corps }\end{array}$ \\
\hline 2007 & 0.782563 & 0.376147 & 1.214857 & 0.369305 & 0.446479 & 1.529518 & 0.868939 \\
\hline 2008 & 0.340334 & 0.3246 & 1.18957 & 0.524124 & 0.173511 & 1.637141 & 1.333803 \\
\hline 2009 & 1.27685 & 0.780914 & 1.863857 & 0.803783 & 0.627117 & 1.162278 & 1.619385 \\
\hline 2010 & 1.180205 & 0.640042 & 2.421029 & 1.493474 & 1.14552 & 0.858521 & 2.412264 \\
\hline 2011 & 1.902189 & 0.427463 & 2.470096 & 2.428211 & 1.328761 & 1.173015 & 4.266479 \\
\hline 2012 & 2.643684 & 1.193797 & 2.906054 & 3.200719 & 1.861679 & 1.208074 & 5.682953 \\
\hline 2013 & 3.310584 & 2.340507 & 3.051388 & 4.081596 & 2.359398 & 1.449113 & 8.09049 \\
\hline 2014 & 1.455124 & 1.221903 & 3.184965 & 5.067095 & 3.206682 & 1.496348 & 12.08045 \\
\hline 2015 & 1.700865 & 1.510773 & 3.745445 & 5.320297 & 3.734356 & 1.779742 & 14.68148 \\
\hline 2016 & 2.027065 & 1.260431 & 3.922444 & 5.578804 & 4.108206 & 2.617598 & 15.12236 \\
\hline
\end{tabular}

Data Sources: Sorted according to the statistical yearbook data of Xinjiang prefectures from 2007 to 2010

According to the data in Table 2, it can be seen that the areas with higher production efficiency in Xinjiang Jujube are the Production and Construction Corps, which has been ranked first from 2007 to 2016, and production efficiency has increased rapidly year by year; in 2016, the Jujube plantation of Xinjiang Production and Construction Corps reached 15 tons / ha, about 15 times that of 2007; the second is Aksu region. In 2016, jujube planting reached 5.6 tons / ha, and the production efficiency was about 18 times higher than 0.36 tons / ha in 2007.It is the region with the fastest growth in jujube planting productivity; the Kashgar region is a region with relatively high production efficiency. In 2016, the jujube planting production efficiency was 4.1 tons / ha, and the production efficiency was about 9 times that of 0.45 tons / ha in 2007; several other regions have also improved to varying degrees, but the increase is relatively small.

\section{PROBLEMS IN THE DEVELOPMENT OF THE JUJUBE INDUSTRY IN XINJIANG}

Jujube belongs to the pillar industry of Xinjiang's characteristic forest and fruit industry. The main production areas of Xinjiang Jujube are located in the Kashgar region, Aksu region, Bazhou region, and Hami and Turpan regions in northern Xinjiang, which have great support for the economic development of southern Xinjiang. It is found through investigation that Xinjiang Jujube industry has not formed systematic continuous data, which brings certain difficulties to the later research of Xinjiang Jujube industry. There are many jujube planting areas in Xinjiang, and jujube quality varies from region to region, and Ruoqiang jujube ranks first in taste and price. At the same time, jujube is also a pillar industry of Ruoqiang's local economy. In February 2019, Jujube in Ruoqiang County and Alar Jujube in Alar both entered the list of advantageous areas for agricultural products with Chinese characteristics. Therefore, through the case analysis of the development status of the jujube industry downstream in Ruoqiang County, and further exploring the restrictive factors of the downstream development of jujube industry in Xinjiang through commonality. 


\subsection{Problems in the Jujube Plantation and Production Area}

Combined with the data on the current state of Jujube's industrial development in Chapter 2 and field investigations and interviews, the main producing areas of Jujube in China are in Xinjiang, and the planting area of Jujube in other provinces has decreased. Jujube is an industry supported by the local government in Xinjiang, and its development momentum has been relatively good. However, although the local government has always issued some relevant policy support, there are still some problems.

It is understood in the field survey that although Ruoqiang County in Xinjiang is a relatively well-known production area in Xinjiang Jujube. Although local farmers generally plant jujube, and the planting area is relatively large, due to lack of relevant jujube planting knowledge, the annual jujube yield is not very stable and the quality is not guaranteed. For example, local jujube companies found in the acquisition that if they have a cooperative relationship with farmers, the farmers may be neglected in the process of planting, which will cause the quality of jujube that year to fall short of requirements. Therefore, the local jujube enterprises cannot guarantee that the farmers that are acquired every year are fixed, and can only make acquisitions based on the actual quality of the jujube of each farmer that year. This will cause many farmers to successfully purchase jujube, and some of them may not be sold or sold at low prices. Therefore, there has been a lack of an effective regulatory and advisory body for jujube cultivation to solve the problem of how to guarantee the quality of jujube.

\subsection{Problems in the Processing and Sales of Jujubes by Leading Enterprises}

There is relatively a small number of jujube enterprises in Ruoqiang County. At present, Qiangdu Jujube Industry Co., Ltd., a well-developed leading company, has a registered capital of 90 million yuan and a total asset of 300 million yuan. It is a key agricultural industrialization key enterprise mainly focusing on jujube series product development, jujube marketing and planting. Sun Juan, Deputy General Manager of Qiangdu Forestry and Farming Group As of the end of 2018, Qiangdu Co., Ltd. has its own jujube plantation area of 30,000 acres and an output of about 650 tons. At the same time, the company also acquires high-quality jujube from other jujube farmers. The annual production of jujube and the acquisition of jujube account for $40 \%$ and $60 \%$ of annual sales. The annual sales of jujube can basically be completed in June or July of the following year. Generally, the stock can be cleared. In 2017, Qiangdu Jujube Industry acquired 1,600 tons of Ruoqiang jujube, including super jujube, first jujube, second jujube, and common jujube. Its sales are mainly first-class jujube and ordinary jujube. Xinjiang's sales market is dominated by high-end jujube. $40 \%$ of the total annual sales, other provinces mainly ordinary low-end dates accounted for $60 \%$ of the total sales of the year. Generally, the sales volume of jujube is relatively good during holidays. For logistics reasons, Qiangdu Jujube Industry is headquartered in Ruoqiang, but in order to facilitate sales in other provinces, a warehouse has been built in Cangzhou, and the capacity of the warehouse can reach 300-400 tons. More than 95\% of Qiangdu's jujube industry's sales model is sold offline, and only Tmall has maintained a sales volume of about $5 \%$ in recent years. The products are mainly based on the original ecological jujube, that is, jujube dried fruits, with the production of some jujube slices, jujube juice and other products. The deep processing of jujube, such as the development of health products has not yet been promoted, but the corresponding research and development of the main products have basically been completed. Although the government strongly supports the jujube industry, the jujube export is still weak. As far as the leading company Qiangdu Jujube Industry is concerned, in 2018, 300 tons of jujube pieces were entrusted to Singapore and 11 tons of jujube were exported to Vietnam.

The sales of Xinjiang jujube enterprises are mainly primary processed products, lack of deep processed products, and the industrial chain is relatively short. For the deep development of jujube, or synthetic health products have not been implemented. Although relevant research institutes have begun research and development and achieved certain results, the supervision of government departments is relatively strict, and enterprises have not yet obtained production approval. In addition, jujube's lack of export sales is basically domestic demand and lack of export support.

\subsection{Problems in the Processing and Sales of Jujubes by Farmers' Cooperatives}

According to the statistics of the Ruoqiang County Forestry Bureau, as of the end of 2018, there were 120 farmer cooperatives, 94 were registered, and the total registered capital reached 585.2567 million. According to President Liu Zhenwei of the Jujube Association, currently there are several well-developed peasant cooperatives in Tarim Cooperative, Luobu Zhuangzi Cooperative and Silk Road Cooperative, especially the Tarim Cooperative. It has been interviewed by CCTV and has formed a certain scale. This played a big role in the promotion of Ruoqiang County jujube. The e-commercebased farmer cooperatives mainly include Han Yupeng Love Health Cooperative, which includes 105 farmers. Each year, they can sell the jujube of the year, but the price is relatively low and belongs to the sales of primary products. The number of jujube purchases of farmers' cooperatives is basically about $20-30$ per year, and the output of jujube purchase is only $10-15 \%$ of the output of jujube in that year. The remaining jujube is basically sold to jujube enterprises in other provinces, and few are processed locally. It can be seen that the role of farmers' cooperatives has not been effectively played.

Currently, although Ruoqiang County has more than 100 farmers' cooperatives. However, there are only 20-30 farmers' cooperatives that actually play a role, and it is limited to the unified purchase of jujube in the hands of farmers in the season, which has not played a role in joint production and joint sales. Only individual farmers' 
cooperatives can have their own sales channels. Most peasant cooperatives only buy jujube and sell it to other jujube enterprises in other provinces and cities, and the profit is very small, only a few dollars a kilogram, which cannot achieve the goal of driving farmers to become rich. In recent years, the income of jujube farmers is very low, and the purchase price per kilogram is about $7-15$ yuan. If one year's input is deducted from the farmers, the profit is extremely low, and farmers' enthusiasm for jujube cultivation is also weakening.

\section{PATH FOR THE TRANSFORMATION AND DEVELOPMENT OF THE JUJUBE INDUSTRY IN XINJIANG IN THE CONTEXT OF THE SILK ROAD ECONOMIC BELT}

From the perspective of industrial development cycle theory, the jujube plantation industry in Xinjiang has gone through a new stage-development stage-mature stage and gradually entered the industry's decline stage. At this time, external factors are urgently needed to intervene. If the industrial transformation and upgrading can be carried out in a timely manner, a new development trend will be carried out at this stage to avoid the decline and decline of the industry. The proposal of the new Silk Road Economic Belt has undoubtedly brought huge opportunities for Xinjiang's development. As the core area of the New Silk Road Economic Belt, Xinjiang faces the window of Central and Western Asia. In the implementation of strategic integration, it is facing great challenges. We can use this opportunity to break through the bottleneck of Xinjiang's jujube industry development. Generally speaking, if an industry wants to break through the bottleneck of industrial development, it is inseparable from the progress of industrial technology, the support of industrial policies, the innovation of industrial organizations, the change of social habits, and the global development of products. Xinjiang jujube industry is currently in a period of decline. Therefore, the following aspects should be transformed and upgraded:

\subsection{Play the Supervision Role of Farmers' Cooperatives in Planting}

There are more or less peasant cooperatives in Jujube planting areas in Xinjiang. However, it is found through visits that the proportion of peasant cooperatives that really play a role is about $5 \%-10 \%$.Nevertheless, in these few farmers' cooperatives, this only played a certain role in the acquisition and sales process, and did not play a practical role in planting planning and technical guidance. Therefore, in the future, the role of farmers' cooperatives should be brought into full play. In addition, it is necessary to popularize the scientific and technological knowledge of jujube planting of farmers during regular agricultural leisure, and to jointly supervise the jujube planting process of farmers. For example, the application of pesticides, bulking agents, etc.is tested in real time, and as far as possible, avoid using less in the case of ecological green environment to ensure the quality of jujube. Only when good jujube quality is ensured in the planting process can we minimize the negative factors in the processing and sales of jujube.

\subsection{Vigorously Develop the "Local Leading Enterprises + SMEs + Farmers' Cooperatives" Model}

The development of the industry is inseparable from the support of large enterprises. Although there are not many local jujube enterprises in Xinjiang, if a large jujube company like Qiangdu can effectively play a leading role, it is bound to accelerate the development of Ruoqiang County's jujube industry. At the same time, the government should also support relatively small local jujube enterprises and cultivate a group of small and medium-sized enterprises with strength and good development prospects as soon as possible. In this way, it is possible for local enterprises to compete with large enterprises in other provinces and cities.

If the "local leading enterprises + SMEs + farmers cooperatives" model can be realized, leading enterprises can mainly build brand effects and create high-end products, while leaving some production tasks to SMEs or organizing SMEs for online sales. This can not only compete with jujube enterprises in other provinces, but also promote the development of local SMEs, and it can be achieved for farmers to increase their income. The Jujube acquired by Qiangdu's farmers each year accounts for $60 \%$ of the company's annual sales, but it is not limited to which farmer's jujube, but randomly selects the better quality of the year. The reason is that the fixed cooperation will cause some jujube farmers to be not responsible for planting, and the quality of jujube is not enough. After the "local leading enterprise + SME + farmer cooperative" model is established, if both jujube associations and farmer cooperatives can achieve effective supervision, strictly control the cultivation process and focus on technical cultivation, then the quality of jujube can naturally be guaranteed. With relatively stable output, companies can formulate relatively stable sales plans and plans. And enterprises can regularly organize jujube planting technology training with farmers' cooperatives to improve farmers' jujube planting level and further promote jujube quality and yield.

\subsection{Utilized Leading Enterprises to Promote the Deep Processing Chain of the Jujube Industry}

According to the survey results, the current jujube on the market is mostly primary products, lacking products for deep processing of jujube. Jujube belongs to agricultural and sideline products with high nutritional value. In addition to being sold in the form of jujube dried fruits, jujube can also be refined and further processed to expand the jujube industry chain. The jujube company of Qiangdu had the idea of deep processing of jujube, and conducted research and development of jujube health products with related research institutes. However, the approval procedures for health products have not been implemented, 
which is a real problem. If relevant departments can strongly support the deep processing of jujube products, promote cooperation between enterprises and scientific research institutes, and develop more jujube products, it can increase the sales of jujube products. At the same time, broadening the sales market of jujube can achieve a substantial increase in sales of jujube, solve the current problem of a single jujube sales variety and short industry chain, and accelerate the transformation and upgrade from primary products to advanced products.

\subsection{Government Sector Should Effectively Promote to Improve the Convenience and Perfection of Transportation Facilities}

As the core area of the New Silk Road, Xinjiang enjoys an advantageous geographical location with five ports and eight countries. If the government can strongly support the construction and improvement of the transportation facilities in the jujube producing area, it will bring more convenience and reduce logistics costs for the logistics and transportation of jujube in Xinjiang. At present, the transportation problem of jujube in Xinjiang has been relatively difficult to solve. The headquarters are located locally, but because many places have only roads. Therefore, the cost of logistics is very high, and there are many uncertain factors, and the time is relatively long. For example, Ruoqiang County had only road transportation before, and it was a first class highway. The timeliness and safety of logistics have not been guaranteed. Although the airport is now built, although the timeliness is fast, the cost of aviation logistics is higher, but economic rail transportation is relatively scarce. Similar problems are found in other regions. Therefore, in order to get rich quickly, we must first improve transportation. Relevant departments can increase the construction of the railway transportation network, connect with the railways to Central Asia and Europe, and lay a preliminary foundation for the sales convenience of jujube.

\section{IMPROVE THE JUJUBE BRAND STRATEGY AND INCREASE TRADE WITH CENTRAL ASIA}

Xinjiang is the link between China and Central Asia. The New Silk Road Economic Belt connects the Asia-Pacific economic circle and the European Union economic circle, and is a bridge connecting many parties. Xinjiang has an excellent geographical location with transport links connecting Central Asia and the European Union. At the same time, there are also multiple ports and free trade zones. In the future Xinjiang Jujube can build its own brand, enhance the brand effect and develop with Central Asian and European companies, and establish friendly cooperative relations. Therefore, it is bound to introduce new technologies, new equipment, and high-skilled R \& $\mathrm{D}$ talents to finish jujube products and expand the length of the industrial chain. Not only that, raising the industry standard of products, integrating with international standards, and selling products globally, trade exchanges can also accelerate the expansion of Xinjiang Jujube's overseas markets and allow Xinjiang's Jujube to enter Central Asia and the European Union. It is necessary to build a Chinese jujube production base, create a brand effect of local enterprises in Xinjiang, realize trade connectivity with Central Asia, expand the sales network of Xinjiang jujube, break through the bottleneck of industrial development, and make Xinjiang jujube go global and become a world jujube production base. This can promote the growth of farmers' income, drive the development of the regional economy, and create products with regional characteristics. Products can be gradually exported from Central Asia to other countries, and finally realize the globalization of product sales and promote the transformation and upgrading of the jujube industry.

\section{CONCLUSION}

This study analyzes the development of jujube industry in China and the current situation of jujube industry in Xinjiang. Combined with field investigations on the problems of enterprises, farmers' cooperatives and farmers in the main jujube producing areas of Xinjiang, the problems in the development of jujube industry in Xinjiang and the bottlenecks of industrial development are analyzed in depth. According to the analysis of existing problems and influencing factors, this article further puts forward suggestions for the transformation and development of Xinjiang's jujube industry. Based on the analysis of this research and the theory of industrial development cycle, the theoretical basis of Xinjiang Jujube's industrial transformation and development is discussed in detail, which also provides a scientific reference and basis for the transformation and development of other agricultural products in Xinjiang.

\section{ACKNOWLEDGMENTS}

This research project was funded by the Young Teacher Training Project of the Education Department of Xinjiang Uygur Autonomous Region --"Research on the Transformation and Upgrading of Xinjiang Jujube Industry in the Context of "Silk Road Economic Belt"" (Project No. XJEDU2016S101).

\section{REFERENCES}

1. Liu Fuyong, Gao Xianqiang, Wu Huanhuan.Design and Implementation of Web-based Information System of Jujube in Southern Xinjiang [J].Jiangsu Agricultural Sciences, 2017, 45 (06): 216-218.

2. Li Zhigang, Yao Tingting.Xinjiang Jujube Industrial Supply Chain Management [J].Jiangsu Agricultural Sciences, 2017, 45 (04): 288-292.

3. Wu Liang, Guo Meiwen.Research on the Innovation of Agricultural Marketing Channel Mode Based on "Internet $+"$ _ Taking Xinjiang Jujube as an Example [J].Price Monthly, 2017 (07): 59-63.

4. Wang Yu, Li Zhanlin, Si Qin, Wang Yundong, Tan Min.Development status and future development ideas of Jujube industry in Xinjiang [J].Rural Science 
and Technology, 2019 (03): 60-64.

5. Bai Xiao, Li Changlin, Gao Yuan, etc.Research on the development status of Xinjiang Jujube industry [J].Consumer Guide, 2019, (45): 118-121.

6. Li Wenchun, Qiao Yuanyuan, Wang Chenghu, Yu Tianzhu, Zhang Junting, Deng Yameng.Problems and control strategies of Xinjiang jujube quality and safety [J].Modern Agricultural Science and Technology, 2019 (23): 230-231.

7. Bai Xiao.Opportunities and challenges of the development of Xinjiang jujube industry in the context of the Silk Road Economic Belt [J].Today's Fortune, 2017 (4): 6-7.

8. Bai Xiao, Gao Yuan, Zhang Rong.Research on the Transformation and Upgrading of Xinjiang Jujube Industry in the Context of "Silk Road Economic Belt" [J].Modern Trade Industry, 2019 (36): 21-22. 